\title{
Numerical Studies on Forecast Error Correction of GRAPES Model with Variational Approach
}

\author{
Dengxin He ${ }^{D},{ }^{1,2}$ Zhimin Zhou, ${ }^{1}$ Zhaoping Kang, ${ }^{1}$ and Lin Liu ${ }^{1}$ \\ ${ }^{1}$ Institute of Heavy Rain, China Meteorological Administration, Wuhan 430074, China \\ ${ }^{2}$ Key Laboratory for Semi-Arid Climate Change of the Ministry of Education, College of Atmospheric Sciences, \\ Lanzhou University, Lanzhou 730000, China \\ Correspondence should be addressed to Dengxin He; whihrhedx@163.com
}

Received 12 January 2019; Revised 18 March 2019; Accepted 16 April 2019; Published 7 May 2019

Academic Editor: Stefano Federico

Copyright (C) 2019 Dengxin He et al. This is an open access article distributed under the Creative Commons Attribution License, which permits unrestricted use, distribution, and reproduction in any medium, provided the original work is properly cited.

To implement deterministic short-range numerical weather forecast error correction, this study develops a novel approach using the variational method and historical data. Based on time-dependency characteristic of nonsystematic forecast error, variational approach is adopted to establish the mapping relation between nonsystematic error series and the prior period nonsystematic error series, so as to estimate nonsystematic error in the future and revise the forecast under the premise of the revision for forecast systematic forecast error. According to the hindcast daily data of geopotential height on $500 \mathrm{hPa}$ generated by GRAPES model on January and July from 2002 to 2010, preliminary analysis is carried out on characteristics of forecast error in East Asia. Further estimation and forecast correction test are conducted for nonsystematic error. The result shows that the nonsystematic forecast error in the GRAPES model has obvious characteristic of state dependency. Nonsystematic forecast error changes along season and the state of weather and accounts for great proportion in total forecast error. Nonsystematic forecast error estimated by variational approach is relatively close to the real forecast error. After nonsystematic correction, the corrected $24 \mathrm{~h}$ and $48 \mathrm{~h}$ forecast of majority samples has a smaller RMSE. Further study on temperature shows a similar result, even comparing to the observational upper air MICAPS data.

\section{Introduction}

As a result of the usage of various observation data, application of advanced data assimilation method [1-3] as well as innovation in computer and forecast technology, the weather forecasting, and numerical simulation has developed significantly in the past decades [4]. However, numerical forecasts still suffer from model dynamic framework, parameterized scheme, and related shortcomings (i.e., initial conditions and boundary conditions for regional models). In order to make a skilful short-range forecast, apart from direct improvement in initial data and models, postprocessing algorithms also work to remove model errors.

A large variety of numerical weather prediction postprocessing methods has been proposed and tested [5-8]. Chou [9] proposed a method combining dynamics and statistics, in which observation is regarded as the solution of the atmosphere model, and solving inverse problem was used to correct the model error. This method was further developed by Huang et al. [10], Ren and Chou [6], and Yu et al. [11]. In the study by Peng et al. [12], the concept of anomaly integration and historical climate data was used, and a novel operational framework was proposed to implement deterministic numerical weather prediction within 15 days. Zupanski and Zupanski [13] proposed a new method for model error estimation combining with ensemble data assimilation method, state augmentation as well as parameter. Recently, model bias correction is also applied to dynamical 4 downscaling of regional climate $[14,15]$ and ensemble forecasts [16-19] to provide reliable probability forecasts and shows obvious improvement.

In 1978, Leith [20] estimated state-dependent model error using empirical statistics, in which model tendency 
error was regarded as linear function of state variable. The statistical model can be acquired from time series of forecast state. Danforth et al. [21] suggested separating the model error into three components: the model bias (obtained by time averaging the error over several years), the periodic (seasonal and diurnal) component of the error, and the nonperiodic error. Danforth and Kalnay [22] indicated that, if the degree of freedom of model is $N$, then the method proposed by Leith needs $N^{3}$ floating point arithmetic in each step, which requires more computation time for the forecast than that in the biased model integration alone. Therefore, he proposed to combine Leith's method with a new computationally inexpensive approach based on SVD (singular value decomposition). The method can be applied at a rather low cost and yields significant forecast improvements. Based on this method (application of SVD), Shao et al. [23] solved this problem by minimization with variational method; forecast error was divided into two parts: systematic error and nonsystematic error, where systematic error is the average of forecast error and the rest part is nonsystematic forecast error. Thus, the solution is more stable and be prone to be added to other constraint conditions (such as background item).

In this paper, we introduce a new forecast error correction approach using variational method. Nonlinear mapping relation between current nonsystematic error series and the prior period nonsystematic error series is established, based on the time tendency of nonsystematic forecast error [24]. The main goals are to (i) estimate nonsystematic forecast error by using the variational approach and (ii) correct forecast error. The hindcast daily data of geopotential height on $500 \mathrm{hPa}$, which was generated by the GRAPES (Global/Regional Assimilation and Forecast System) model in January and July from 2001 to 2010, are used to analyse the primary feature of space distribution, estimate the nonsystematic forecast error, and correct the forecast. At last, the analysis data from NCEP (National Centers for Environmental Forecast) FNL (Final Operational Global Analysis) are used as real atmosphere to assess the result. In addition, the correction of temperature on $500 \mathrm{hPa}$ is conducted to compare the improvement with observational data (MICAPS upper air data). The result shows that (i) the nonsystematic forecast error in the GRAPES model has obvious characteristic of state dependency, changes along season and the state of weather, and accounts for great proportion in total forecast error; (ii) nonsystematic forecast error estimated by variational approach is relatively close to the real forecast error, and the correction is effective; and (iii) study on temperature shows a similar result, even comparing to the upper-air observation from MICAPS.

\section{Materials and Methods}

2.1. Brief Description of the Numerical Model. Global/Regional Assimilation and Prediction (GRAPES) (version: GRAPES_Meso 3.0) is a numerical weather prediction system which was independently developed by Chinese Academy of Meteorological Sciences. The system has been running on the national/regional meteorological service center and plays a very important role in the actual weather business [25].

2.2. Data and Forecast Error. The data used in this paper include (1) the hindcast daily dataset generated by the GRAPES model with horizontal resolution of $1^{\circ} \times 1^{\circ}$ from 2002 to 2010; (2) the NCEP FNL data product; and (3) the upper air observation from MICAPS (Meteorological Information Comprehensive Analysis and Process System).

The test area is East Asia $\left(10 \sim 60^{\circ} \mathrm{N}, 70 \sim 140^{\circ} \mathrm{E}\right)$. The experimental data are the hindcast daily data of geopotential height on $500 \mathrm{hPa}$ generated by GRAPES in January and July from 2002 to 2010. Analysis data from NCEP FNL are used as criterion to assess the result. The forecast error can be calculated as the difference between GRAPES forecast $x_{k}^{f}$ and FNL analysis data $x_{k}^{f}$ (where $k$ donates the position of the sample in the time series):

$$
e_{k}=x_{k}^{t}-x_{k}^{f}
$$

The forecast error can be separated into two parts: systematic error $\bar{e}$, the mean of the training samples, which indicates the seasonal character of the forecast error, and nonsystematic error $e_{k}^{\prime}$, the anomaly. The system forecast error $\bar{e}$ can be generated by averaging the forecast error $e_{k}$ in a period, and nonsystematic error is the residual part:

$$
e_{k}^{\prime}=e_{k}-\bar{e} \text {. }
$$

There are totally 279 samples of $24 \mathrm{~h}(48 \mathrm{~h})$ nonsystem forecast error of January (July). In the design of experiment, 31 samples of January (July) of 2008 (or 2009, or 2010) are, respectively, used as test samples, and the rest samples of January (July) are used as training samples.

2.3. Characteristic Analysis of Nonsystematic Error. To realize the urgency of nonsystematic error correction, $24 \mathrm{~h}$ and $48 \mathrm{~h}$ forecast error samples in January and July from 2008 to 2010 are used to calculate the proportion of nonsystematic error in forecast error. For example, as for 31 samples' 24 h forecast error in January 2008, the calculation method is as follows: first of all, as for the ith grid point in sample $k$, the proportion $r_{i, k}$ of nonsystematic error in forecast error of this grid point is

$$
r_{i, k}=\left|\frac{e_{i, k}^{\prime}}{e_{i, k}}\right|=\left|\frac{e_{i, k}^{\prime}}{\overline{e_{i, k}}+e_{i, k}^{\prime}}\right|,
$$

where $e_{i, k}$ is the forecast error and $e_{i, k}^{\prime}$ is the nonsystematic error. When $e_{i, k}^{\prime}=0, r_{i, k}=\left|e_{i, k}^{\prime} / e_{i, k}\right|=0$. Consider that the calculation is meaningless when $e_{i, k}=0, r_{i, k}$ at this situation can be calculated according to the following equation:

$$
r_{i, k}=\left|\frac{e_{i, k}^{\prime}}{\overline{e_{i, k}}+e_{i, k}^{\prime}}\right| \geq \frac{1}{\overline{e_{i, k}} / e_{i, k}^{\prime}+1} .
$$

The average of $r_{i, k}$ for all grid points in 31 samples can be used to obtain the proportion $r$ of $24 \mathrm{~h}$ nonsystematic error in January 2008: 


$$
r=\frac{1}{n x * n t} \sum_{k=1}^{k=n t} \sum_{i=1}^{i=n t} r_{i, k} .
$$

Equation (4) shows that $r$ is actually the lower limit of proportion for nonsystematic error in forecast error.

2.4. Methodology. According to the characteristic of time dependency of nonsystematic error series, variational method can be used to establish the mapping relation between the current nonsystematic error $e_{k}^{\prime}$ and the prior period nonsystematic error $e_{k-1}^{\prime}$ (one day before), then estimate nonsystematic error in the future. The method is as follows.

Assume that there is a mapping relation $H$, then a linear operator of statistical relation between $e_{k}^{\prime}$ and $e_{k-1}^{\prime}$ is

$$
e_{k-1}^{\prime}=H e_{k}^{\prime},
$$

where $e_{k}^{\prime}$ and $e_{k-1}^{\prime}$ can be expressed as an expansion of $p$ orders, respectively:

$$
\begin{aligned}
e_{k}^{\prime} & =\sum_{i=1}^{p} \alpha_{i} b_{i}^{e}=b^{e} \alpha, \\
e_{k-1}^{\prime} & =\sum_{i=1}^{p} \alpha_{i} b_{i}^{f}=b^{f} \alpha,
\end{aligned}
$$

where $\alpha$ is the vector consisting of expansion coefficients and $b=\left(\left(b^{e}\right)^{T}, b^{f T}\right)^{T}$ is the orthogonal base vector generated from the two sets of the training samples' nonsystematic forecast error series by the SVD technique. $b^{e}$ and $b^{f}$ are the base vector of the current nonsystematic error series and the prior period nonsystematic error series, respectively. Specific calculation method of orthogonal base vectors is as follows: first of all, acquire nonsystematic error $e_{i}^{\prime}(i=1,2, \ldots, M)$ of $M$ training samples and nonsystematic error $e_{k-1}^{\prime}(i=1,2$, $\ldots, M)$ at prior period. Then, couple these two sets and get a column vector $a_{i}=\left(e_{k}^{\prime}, e_{k-1}^{\prime T}\right)^{T}$, so we get a matrix $A$ with $M$ column vectors. Applying the SVD technique on matrix $A$, we can obtain a set of eigenvalue and left and right eigenvector correspondingly. Arrange the eigenvalue in the order from large to small. The eigenvector $b_{i}(i=1, p)$ of left eigenvector set $B$, corresponding to the first $p$ nonzero eigenvalue, is the singular vector needed in (7) and (8). The issue of estimating nonsystematic forecast error can be expressed in the form of minimizing the objective function as follows:

$$
J\left(e_{k}^{\prime}\right)=e_{k}^{\prime T} E^{-1} e_{k}^{\prime}+\left[e_{k-1}^{\prime}-H e_{k}^{\prime}\right]^{T} O^{-1}\left[e_{k-1}^{\prime}-H e_{k}^{\prime}\right],
$$

where $E$ is the covariance matrix of the background error, and according to Equation (7), it can be expressed as $E \approx A_{e} A_{e}^{T} /(M-1)=b^{e} \Lambda_{P}^{2}\left(b^{e}\right)^{T} /(M-1) . \quad O$ is the covariance matrix of the observation error, which is related to the form of $e_{k-1}^{\prime}$, the number of training samples, and so on, and it is hard to gain the accurate estimation. We assume that the order of this mapping relationship is similar to the forecast error, and we have already standardized all the variables according to their variance. So, the covariance is equal to 1 . The objective function (9) can be expressed as follows:

$$
J(\alpha)=(M-1) \alpha^{T} \Lambda_{P}^{-2} \alpha+\left[e_{k-1}^{\prime}-b^{f} \alpha\right]^{T}\left[e_{k-1}^{\prime}-b^{f} \alpha\right] .
$$

The coefficient $\alpha$ can be acquired from minimizing objective function above, and then, Equation (7) can be used to obtain nonsystematic error $e_{k}^{\prime}$.

2.5. Forecast Error Correction Verification. The method's ability of estimating nonsystematic error can be assessed by the analysis of forecast correction effects. For the forecast $x_{k}$, after adding systematic error and nonsystematic error estimation, the corrected forecast is expressed as

$$
x_{k}^{s}=x_{k}+\bar{e}+e_{s} \text {. }
$$

The RMSE of $x_{k}^{s}$ is calculated as follows:

$$
\operatorname{RMSE}_{k}^{s}=\sqrt{\frac{1}{n x} \sum_{i=1}^{i=n x}\left(x_{k, i}^{s}-x_{k, i}^{t}\right)^{2}},
$$

where the analysis field $x_{k}^{t}$ is used as true field. The smaller the RMSE is, the closer the corrected forecast is to the FNL field and the better the correction effects is.

\section{Results and Discussion}

3.1. Characteristic Analysis of Forecast Error. To have a preliminary analysis of forecast ability of the GRAPES model, the error calculation method in Section 2.3 is adopted to generate the systematic forecast error and nonsystematic forecast error of geopotential height on $500 \mathrm{hPa}$ of $24 \mathrm{~h}$ and $48 \mathrm{~h}$ forecast in January and July from 2002 to 2010 in East Asia.

3.1.1. Spatial Characteristic Analysis of Systematic Error. Systematic error field of $24 \mathrm{~h}$ and $48 \mathrm{~h}$ forecast of the GRAPES model in January and July over East Asia region is given in Figure 1. It shows that systematic error of $24 \mathrm{~h}$ and $48 \mathrm{~h}$ of geopotential height on $500 \mathrm{hPa}$ in January has a tendency of gradually decreasing from positive value to negative value from south to north with the increase of latitude. The region of the negative value is larger, which indicates that the forecast value of the GRAPES model in low-latitude region is relatively lower and the forecast value in most regions of East Asia (to the north of $20^{\circ} \mathrm{N}$ and to the west of $120^{\circ} \mathrm{E}$ ) is relatively higher especially in the northeast side of Qinghai-Tibet Plateau. The systematic error of $24 \mathrm{~h}$ and $48 \mathrm{~h}$ forecast of geopotential height on $500 \mathrm{hPa}$ in July illustrates a tendency of gradual decrease from positive value to negative value from south to north with the variation of latitude. The figure of forecast in the GRAPES model is relatively lower than the FNL field in the region of south of $40^{\circ} \mathrm{N}$ especially in Qinghai-Tibet Plateau, among which the maximum values of $24 \mathrm{~h}$ and $48 \mathrm{~h}$ systematic forecast error are, respectively, $22 \mathrm{gpm}$ and $28 \mathrm{gpm}$. It means that the GRAPES model may have defects in description of the 


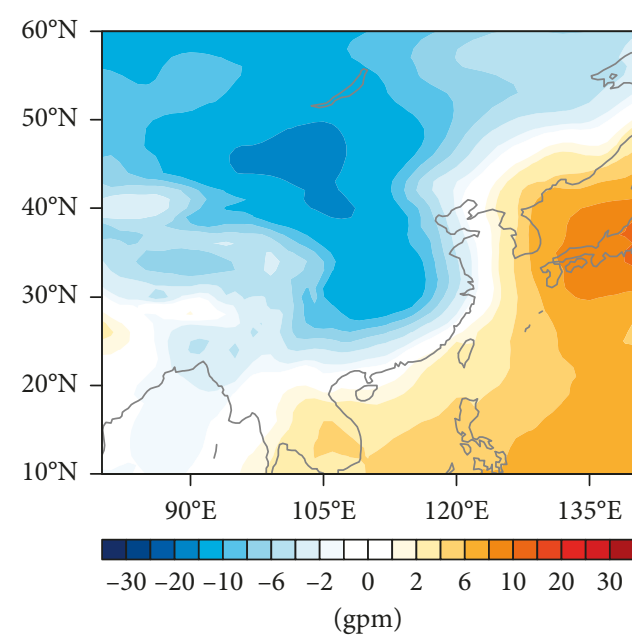

(a)

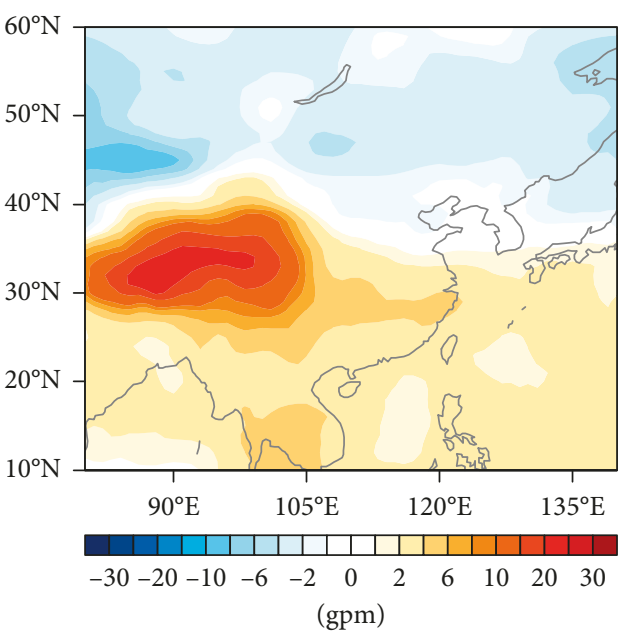

(c)

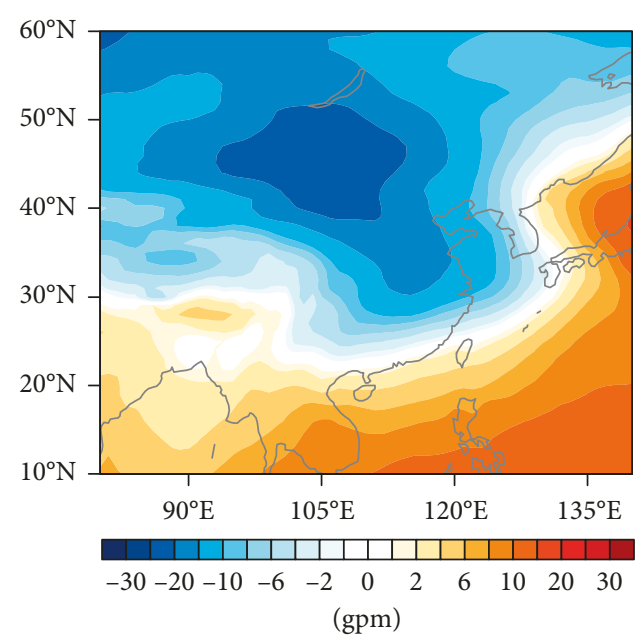

(b)

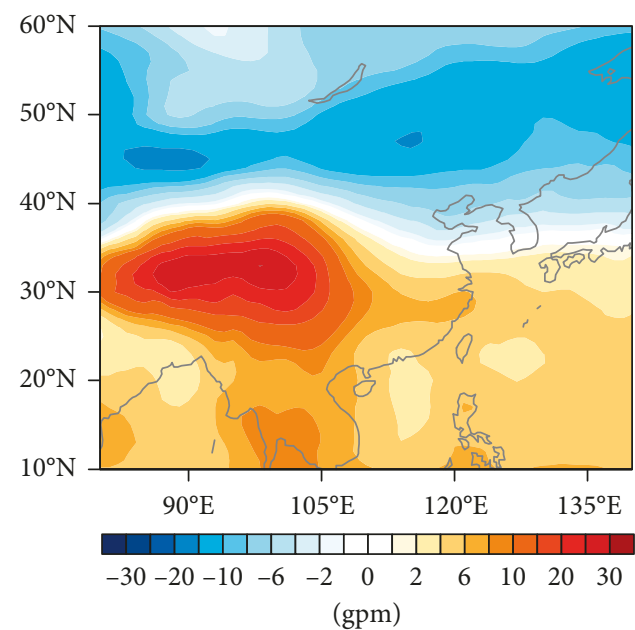

(d)

FigURE 1: Systematic error of geopotential height on $500 \mathrm{hPa}$ in January and July (unit: gpm): (a) $24 \mathrm{~h}$ forecast in January; (b) $48 \mathrm{~h}$ forecast in January; (c) $24 \mathrm{~h}$ forecast in July; (d) $48 \mathrm{~h}$ forecast in July.

dynamical and thermodynamic process in the large-scale terrain region.

The similarity of distribution and the difference of value between $48 \mathrm{~h}$ and $24 \mathrm{~h}$ systematic error indicate that the systematic error will increase with the extension of forecasting period. It is clear that the systematic error of geopotential height on $500 \mathrm{hPa}$ of the GRAPES model has obvious seasonal difference between January and July.

3.1.2. Characteristic Analysis of Nonsystematic Error. Preliminary analysis is carried out on the spatial distribution characteristic of nonsystematic error and the proportion of it in forecast error.

Nonsystematic error fields of $24 \mathrm{~h}$ forecast of geopotential height on $500 \mathrm{hPa}$ of several random samples are specified in Figure 2. It can be seen that nonsystematic error at different time has obvious difference in spatial distribution characteristics, and it has an obvious flow-dependent characteristic. The magnitude of the nonsystematic error at the same forecasting period is basically the same as that of the systematic error. The nonsystematic error of $48 \mathrm{~h}$ forecast has a similar feature and a larger value.

The proportion of $24 \mathrm{~h}$ and $48 \mathrm{~h}$ nonsystematic error of geopotential height on $500 \mathrm{hPa}$ in total forecast error in January and July from 2008 to 2010 in East Asia is given in Table 1 . It shows that the proportion of $24 \mathrm{~h}$ nonsystematic error in January and July is all about 50\%, among which the value in July 2010 is the highest, up to $55.046 \%$. The proportion of $24 \mathrm{~h}$ nonsystematic error is slightly higher than that of $48 \mathrm{~h}$ nonsystematic error. To some extent, this indicates that, while the forecasting period is shorter, the proportion of nonsystematic error is greater. It is important and necessary to correct the nonsystematic error component in forecast error.

3.2. Sensitivity Experiments of Truncation Order of Variational Method. Equation (7) indicates that the nonsystematic error can be expressed approximately by a truncated expansion of the base vectors; the truncation order is an important factor that influences the effects of the method in estimation of 


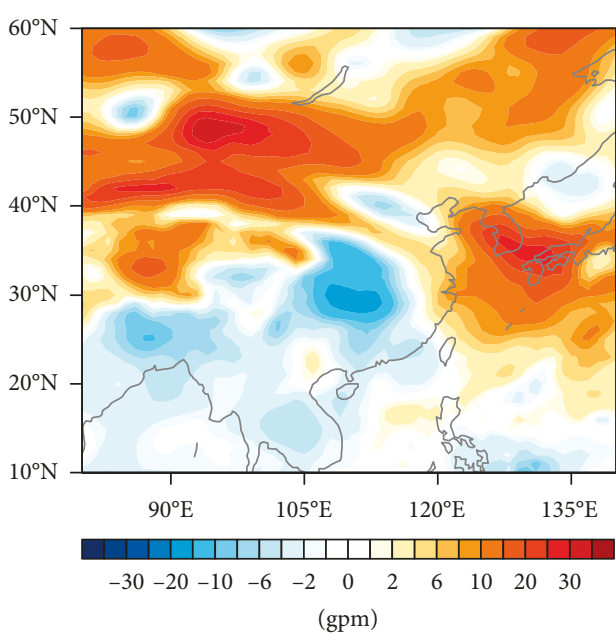

(a)

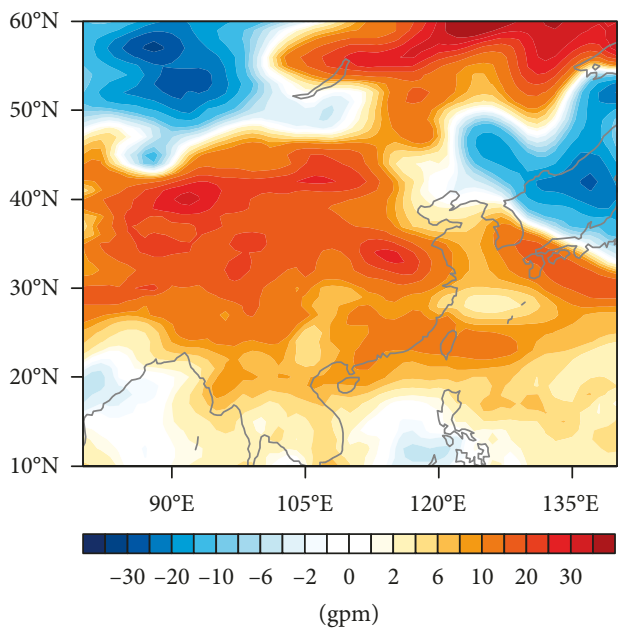

(c)

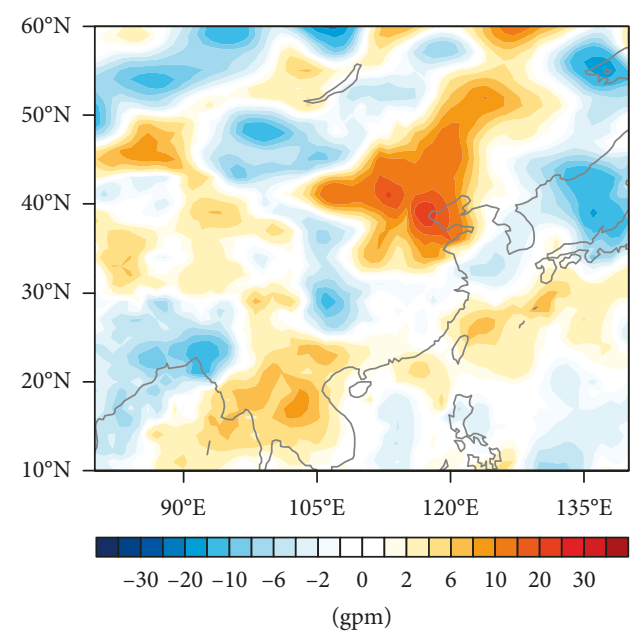

(b)

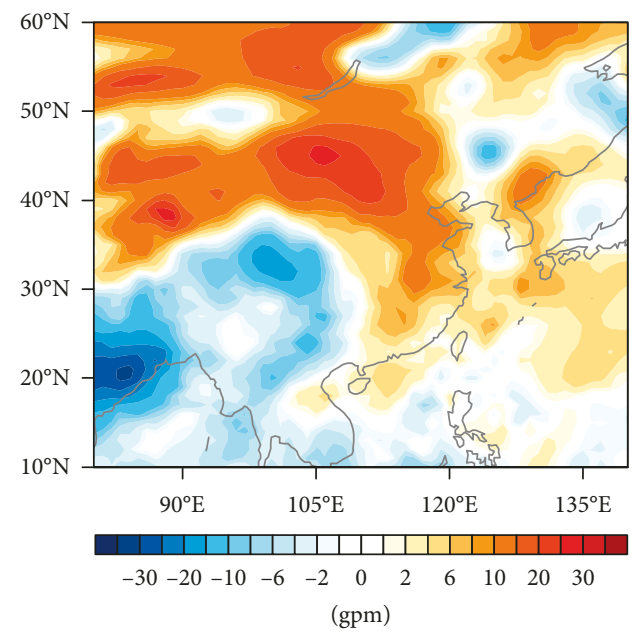

(d)

FIGURE 2: 24 h nonsystematic error of geopotential height on 500 hPa (unit: gpm) (a) January 17, 2008; (b) July 26, 2009; (c) January 15, 2010; (d) July 24, 2010.

TABLE 1: Proportion of nonsystematic error in total forecast error of geopotential height on $500 \mathrm{hPa}$.

\begin{tabular}{lcc}
\hline Test month & 24h forecast $(\%)$ & $48 \mathrm{~h}$ forecast $(\%)$ \\
\hline 2008 Jan. & 50.786 & 47.521 \\
2009 Jan. & 49.696 & 46.905 \\
2010 Jan. & 49.911 & 47.519 \\
2008 Jul. & 54.694 & 45.750 \\
2009 Jul. & 53.386 & 45.631 \\
2010 Jul. & 55.046 & 47.454 \\
\hline
\end{tabular}

nonsystematic forecast error. Therefore, sensibility experiments are carried out to determine the number of truncation order at first, with truncation orders ranging from 10 to 70 in steps of 5 each. Forecast correction result shows that, when the truncation order is from 20 to 40, the average of RMSE of forecast is relatively smaller, which is given in Table 2. It indicates that, when the truncation order is 30 , the average of RMSE after correction of nonsystematic error is the smallest, and correction effects are the best. Therefore, the figure of 30 is picked as the
TABLE 2: Average of RMSE of geopotential height on $500 \mathrm{hPa}$ after correction of nonsystematic error for test samples with different truncation orders (unit: gpm).

\begin{tabular}{lcccccc}
\hline Test type & & $R=20$ & $R=25$ & $R=30$ & $R=35$ & $R=40$ \\
\hline \multirow{4}{*}{ 24 h of January } & 2008 & 8.475 & 8.440 & 8.376 & 8.370 & 8.406 \\
& 2009 & 7.925 & 7.876 & 7.930 & 7.937 & 8.003 \\
& 2010 & 8.128 & 8.097 & 8.110 & 8.107 & 8.094 \\
\hline \multirow{3}{*}{ 44 h of July } & 2008 & 7.035 & 7.011 & 6.984 & 6.968 & 6.950 \\
& 2009 & 6.852 & 6.813 & 6.811 & 6.813 & 6.804 \\
& 2010 & 7.003 & 6.974 & 7.024 & 7.015 & 7.016 \\
\hline \multirow{3}{*}{48 h of January } & 2008 & 13.908 & 13.840 & 13.786 & 13.917 & 13.929 \\
& 2009 & 14.638 & 14.508 & 14.438 & 14.485 & 14.426 \\
& 2010 & 14.335 & 14.229 & 14.161 & 14.093 & 14.157 \\
\hline \multirow{3}{*}{ 48 h of July } & 2008 & 11.403 & 11.382 & 11.397 & 11.333 & 11.307 \\
& 2009 & 12.008 & 12.103 & 12.038 & 12.081 & 12.107 \\
& 2010 & 11.702 & 11.769 & 11.886 & 11.847 & 11.871 \\
\hline
\end{tabular}

truncation order in variation method and to further analyse the method's ability of estimating nonsystematic error and forecast correction effects. 
3.3. Prediction of Nonsystematic Error. In this part, several examples are taken to analyse estimation effects of variational approach for $24 \mathrm{~h}$ and $48 \mathrm{~h}$ nonsystematic error.

3.3.1. Estimation of $24 \mathrm{~h}$ Nonsystematic Error. Estimation of nonsystematic error and the real one of $24 \mathrm{~h}$ forecast of geopotential height on $500 \mathrm{hPa}$ on July 6, 2010, are illustrated in Figure 3. It shows that the method has favourable estimation ability for the nonsystematic error of this sample. The estimated value has basically consistent spatial distribution characteristic with that of the real one. For example, in the negative value area in the north of Japan Sea, the positive value area of Mongolia, and other main big value regions, they have good consistency with real field, not only the distribution but also magnitude, even though estimated value is a little smaller.

Calculate the RMSE of forecast before correction, after correction of systematic error, and after correction of nonsystematic error. The RMSE of this sample sees a fall from $9.610 \mathrm{gpm}$ to $6.870 \mathrm{gpm}$ after correction of systematic error, and it goes down to $5.848 \mathrm{gpm}$ after further correction of nonsystematic error. It means that the estimation of nonsystematic error of this sample by variational approach is effective. The estimated value has main characteristic of nonsystematic value, and the correction can effectively improve the forecast based on systematic error correction.

3.3.2. Estimation of $48 \mathrm{~h}$ Nonsystematic Error. Figure 4 is the nonsystematic error field and the one estimated by variational approach of nonsystematic error of $48 \mathrm{~h}$ forecast of geopotential height on $500 \mathrm{hPa}$ on January 15, 2010. It indicates that the distribution pattern of the nonsystematic error estimated by variational approach of this sample is much closer to the real field, similar to the sample above. The negative value area in northeast and Xinjiang in China and the positive value area near Qinghai-Tibet Plateau are obviously consistent with the real field, and the estimated value of nonsystematic error of this sample is much closer to the real. Variational approach can estimate forecast error effectively. The RMSE of GRAPES forecast field is $15.104 \mathrm{gpm}$, decreasing to $12.843 \mathrm{gpm}$ after correction of systematic error and further decreasing to $10.320 \mathrm{gpm}$ after correction of nonsystematic.

3.4. Verification with NCEP FNL Data. RMSE before forecast correction, after correction of systematic error, and after correction of nonsystematic error by variational approach is statistically analysed to access the effect of correction.

3.4.1. Analysis of $24 \mathrm{~h}$ Forecast Error Correction Effects. RMSE before forecast correction (GRADES), after correction of systematic error (SC), and after correction of nonsystematic error estimated by variational approach (NSEC) of $24 \mathrm{~h}$ forecast of geopotential height on $500 \mathrm{hPa}$ in January and July of 2008, 2009, and 2010 is illustrated in Figure 5. Based on correction of systematic error, forecast corrected by variational approach can effectively improve forecast accuracy further.
For example, the RMSE of 2010 July (Figure 5(f)) shows that, after correction of systematic error, 31 samples see a fall in RMSE. After further correction of forecast by the nonsystematic error estimated by variational approach, RMSE of 28 samples further decreases. Moreover, compared with RMSE, after correction of systematic error, 27 samples show a drop of RMSE after correction of nonsystematic error. The increase of the other 4 individual samples' RMSE is relatively tiny after correction of nonsystematic error. The correction effects of other months have similar results. Shao et al. [23] came up with the method of error correction by using the variational approach to build the relationship between the forecast fields combination (forecast $x_{k}^{f}$ and forecast tendency $x_{k}^{f}-x_{k-1}^{f}$ ) and the forecast error primitively. So, the forecast error correction result conducted by this scheme is also illustrated in Figure 5 (shorted as NSEC-DEM, the green lines). It has the ability to improve the forecast skill based on the systematic error correction, while is not as stable as the scheme in this paper (by building the relationship between the nonsystematic error series and the prior period nonsystematic error series).

Table 3 is the average of RMSE after GRAPES forecast, correction of systematic error, and correction of nonsystematic error for different months. For instance, the average figure of RMSE of GRAPES in January 2008 is $11.263 \mathrm{gpm}$, and it decreases to $9.489 \mathrm{gpm}$ after system correction and then goes down to $8.376 \mathrm{gpm}$ after correction of nonsystematic error. The nonsystematic error correction of DEM also shows an improvement based on the correction of systematic error, while its RMSE average is a little bigger than the approach we used in this paper. Experiments in other years have similar results. Correction of nonsystematic error can obviously improve forecast effects based on correction of systematic error.

Table 4 is the distribution of the ratios of RMSE of $24 \mathrm{~h}$ forecast after systemic error correction or after nonsystematic error correction to the RMSE of GRAPES model forecast in January and July of 186 samples. The ratios of three correction schemes are basically within the range below 1. The number of effective samples (the ratio is less than 1) of systematic error correction is 171, among which there are 161 samples further improved after correction of nonsystematic error. In 15 samples with invalid correction of systematic error, there are 14 samples improved after correction of nonsystematic error. The total number of valid samples after correction of nonsystematic error increases to 179. In this experiment, after systematic error correction, the number of samples with forecast obviously improved (the ratio is less than 0.8 ) is 94 . The number increases to 133 after correction of nonsystematic error. Besides, after correction of nonsystematic error, the number of samples with invalid correction (the ratio is above 1 ) decreases from 15 to 7 . The nonsystematic correction of nonsystematic error correction of DEM presents a similar result while the trend of the distribution moving to the smaller interval is not that significant. The correction of nonsystematic error by variational approach can increase the number of valid samples in forecast and reduce the number of samples with unobvious or invalid correction effects, and it is more efficient than the nonsystematic error correction approach of DEM. 


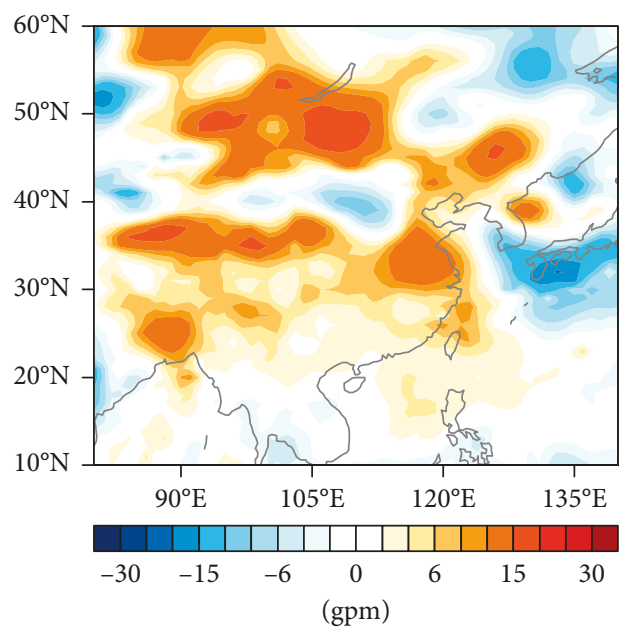

(a)

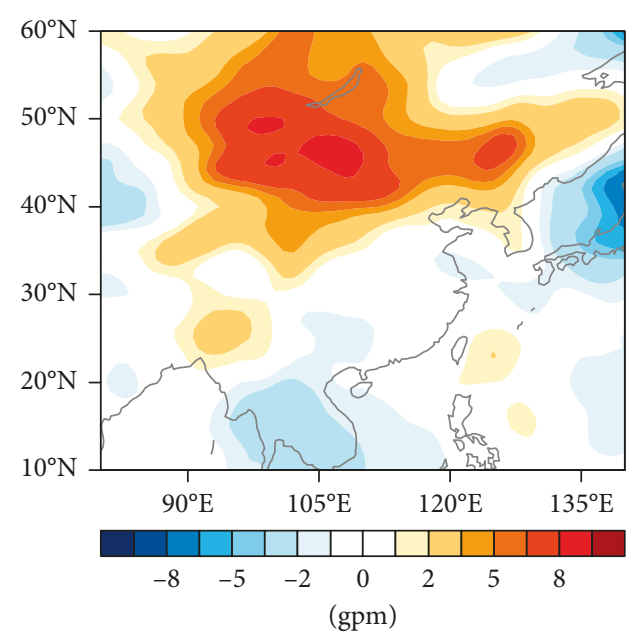

(b)

FiguRE 3: $24 \mathrm{~h}$ nonsystematic error of geopotential height on $500 \mathrm{hPa}$ on July 6, 2010 (unit: gpm): (a) nonsystematic error and (b) nonsystematic error estimated by variational approach.

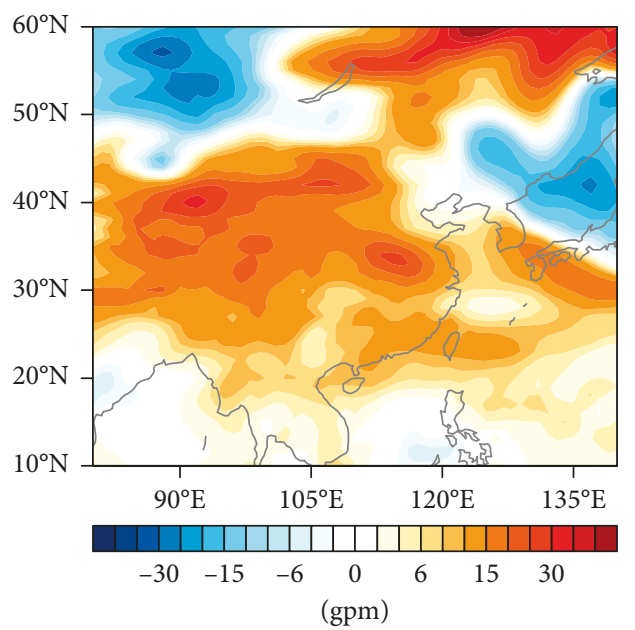

(a)

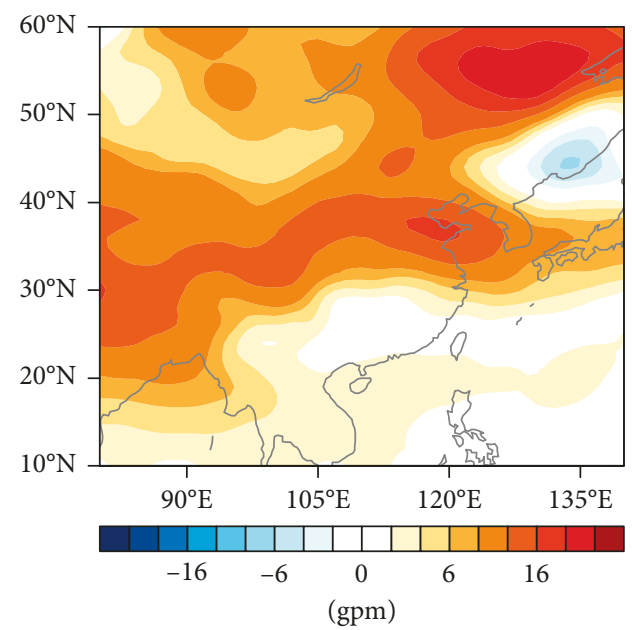

(b)

FIGURE 4: $48 \mathrm{~h}$ nonsystematic error of geopotential height on $500 \mathrm{hPa}$ on January 15, 2010 (unit: gpm): (a) nonsystematic error and (b) nonsystematic error estimated by variational approach.

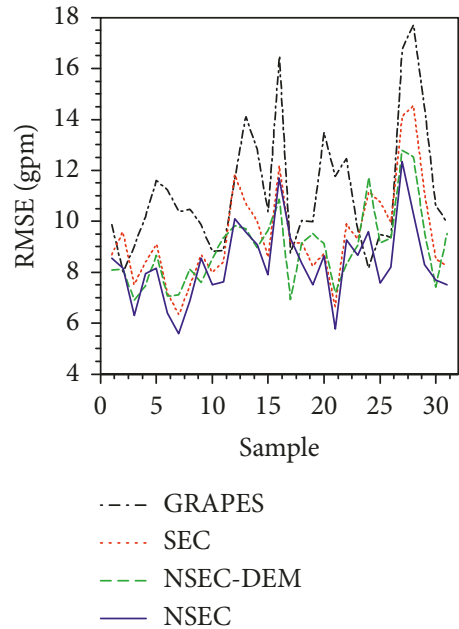

(a)
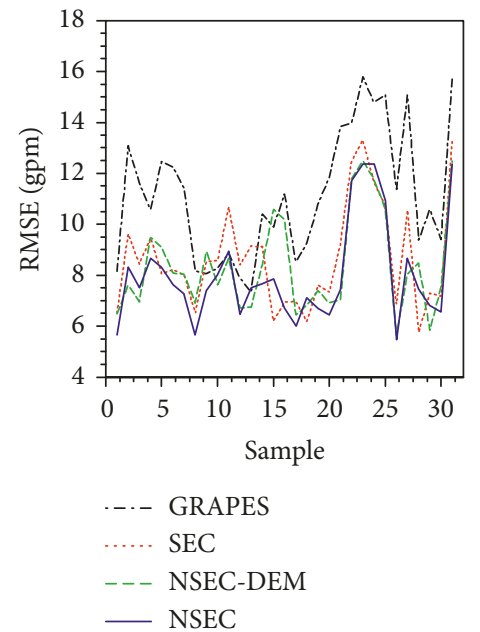

(b)

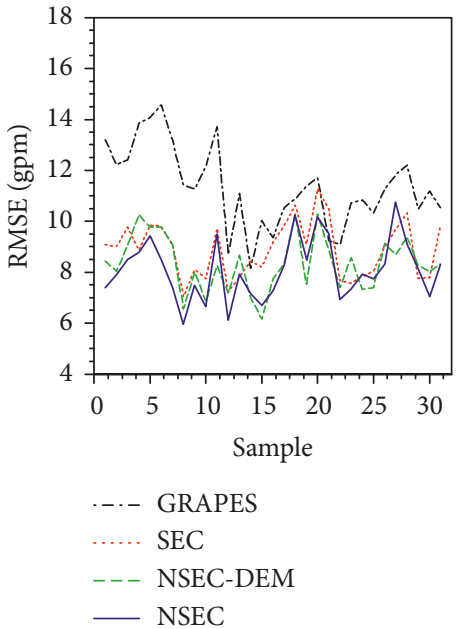

(c)

Figure 5: Continued. 


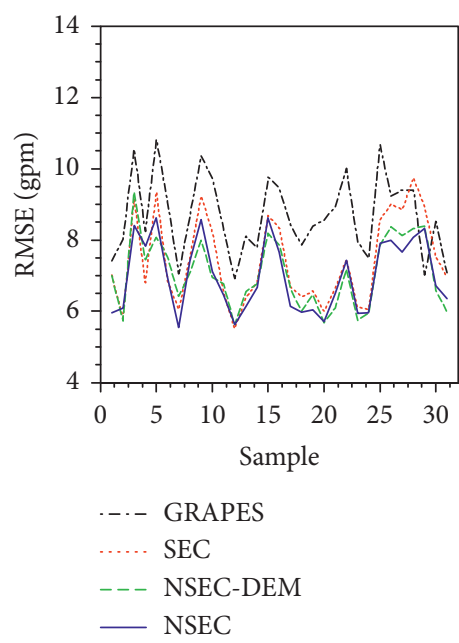

(d)

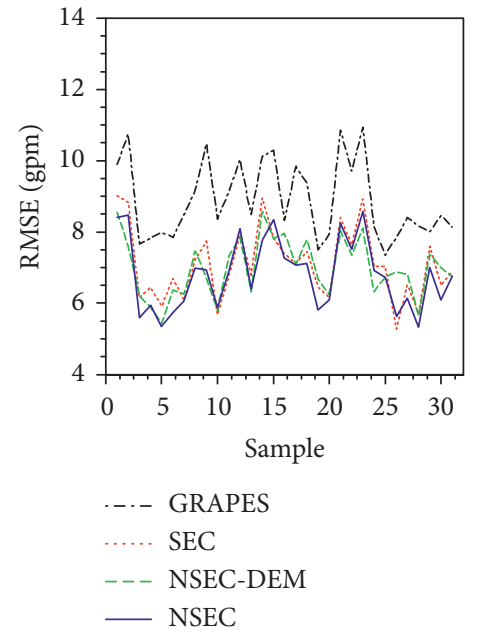

(e)

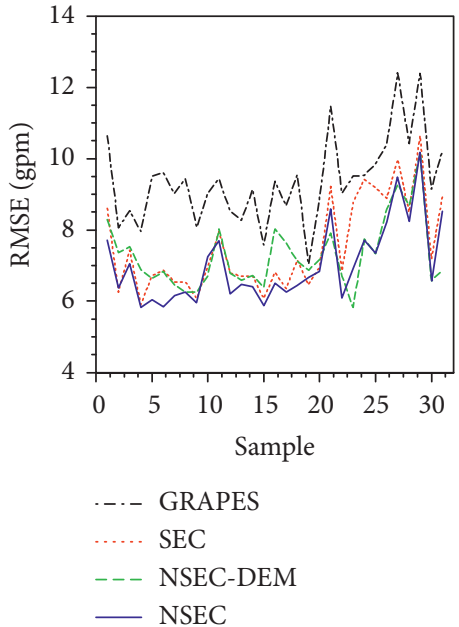

(f)

Figure 5: RMSE of $500 \mathrm{hPa}$ geopotential height of $24 \mathrm{~h}$ forecast at January (a, b, and c) and July (d, e, and f) of 2008, 2009, and 2010. The black lines (GRAPES) denote GRAPES model forecast, red lines (SC) to the forecast after system correction, blue lines (NSC) to the forecast after correction of nonsystematic error, and green lines (NSEC-DEM) to the forecast after correction of nonsystematic error by DEM approach [23].

TABle 3: Average of RMSE of test samples of geopotential height on $500 \mathrm{hPa}$ (unit: gpm).

\begin{tabular}{lcccc}
\hline Test month & GRAPES model & Systematic error correction & Nonsystematic error correction of DEM & Nonsystematic error correction \\
\hline 2008 Jan. & 11.263 & 9.489 & 8.928 & 8.376 \\
2009 Jan. & 11.077 & 8.588 & 8.022 & 7.930 \\
2010 Jan. & 11.306 & 8.854 & 8.494 & 8.110 \\
2008 Jul. & 8.686 & 7.415 & 7.173 & 6.984 \\
2009 Jul. & 8.887 & 7.104 & 7.008 & 6.811 \\
2010 Jul. & 9.380 & 7.532 & 7.208 & 7.024 \\
\hline
\end{tabular}

TABLE 4: Distribution of ratios of RMSE of corrected $24 \mathrm{~h}$ forecast of geopotential height on $500 \mathrm{hPa}$ to the forecast of GRAPES model.

\begin{tabular}{lccccccc}
\hline Correction process & $0.4-0.5$ & $0.5-0.6$ & $0.6-0.7$ & $0.7-0.8$ & $0.8-0.9$ & $0.9-1.0$ & $>1.0$ \\
\hline Systematic error & 0 & 1 & 26 & 67 & 57 & 20 & 15 \\
Nonsystematic error of DEM & 0 & 9 & 32 & 67 & 49 & 23 \\
Nonsystematic error & 2 & 12 & 35 & 84 & 38 & 8 \\
\hline
\end{tabular}

3.4.2. Analysis of $48 \mathrm{~h}$ Forecast Error Correction Effects. Similar to Figure 5, Figure 6 is the RMSE of geopotential height of $48 \mathrm{~h}$ forecast on $500 \mathrm{hPa}$ in January and July of 2008, 2009, and 2010 before and after correction. A case study of July 2010 (Figure 6(f)) shows the RMSE of 30 samples decreases sharply, and the correction of only one sample is invalid after correction of systematic error. RMSE of forecast after nonsystematic error correction further decreases, and all samples are effectively corrected, which includes the invalid samples after systematic error correction. In this case, based on correction of systematic error, 24 samples' RMSE further reduces which shows that variational approach is valid for correction of height field. Other tests have similar results.

The average of RMSE of forecast before correction, after correction of systematic error, and correction of nonsystematic error of all test samples in each experiment is shown in Table 5. The average of RMSE of GRAPES model in
January 2008 is 17.297 gpm. After system correction, it decreases to $15.406 \mathrm{gpm}$. After further correction of nonsystematic error by variational approach, it declines to $13.786 \mathrm{gpm}$. It can be seen that the correction of nonsystematic error can effectively improve forecast effects. Correction effects of forecast by variational approach in other years are similar to the result in January 2008.

Table 6 is the distribution of ratios of $48 \mathrm{~h}$ forecast in January and July of 186 samples. It indicates that the ratio of valid correction of systematic error of $48 \mathrm{~h}$ forecast is $88.172 \%$, increasing to $97.311 \%$ after nonsystematic error correction. The number of samples corrected effectively (the ratio is below 0.8 ) by nonsystematic error increases from 95 to 130 , and the number of samples with invalid correction reduces from 22 to 5 . Variational approach further decreases the RMSE and improves forecast effects based on systematic error correction. 


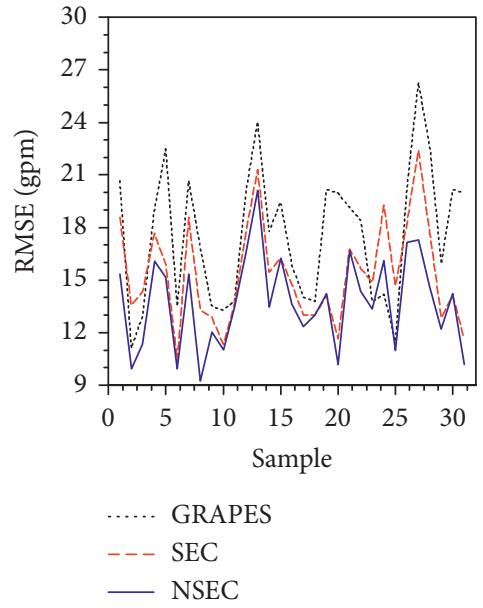

(a)

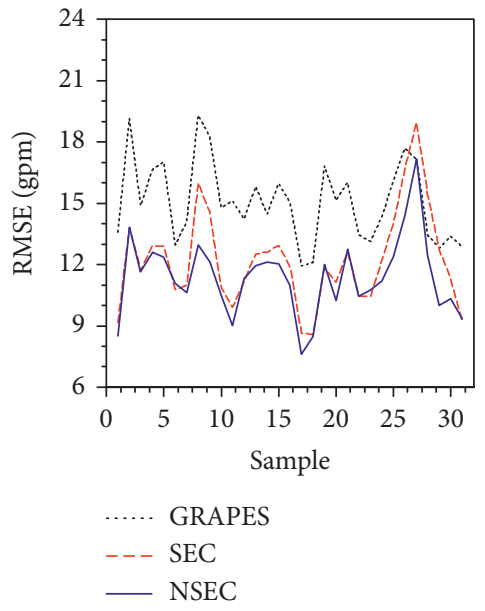

(d)

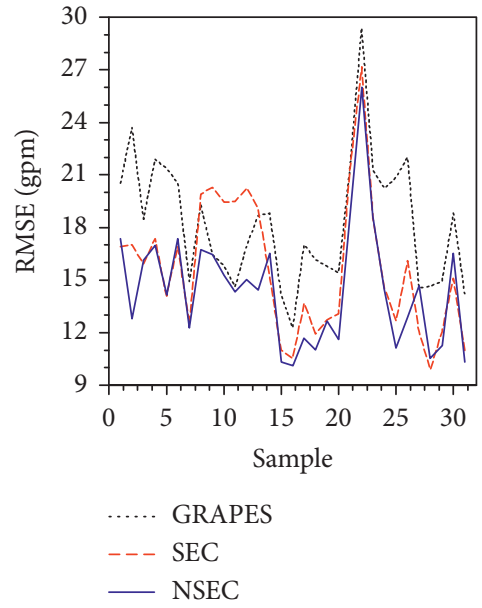

(b)

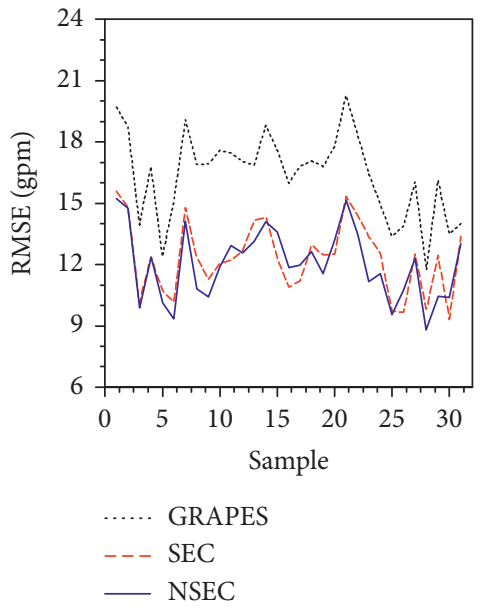

(e)

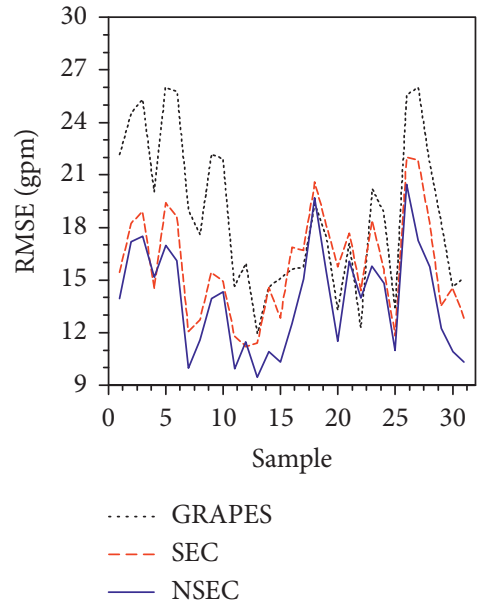

(c)

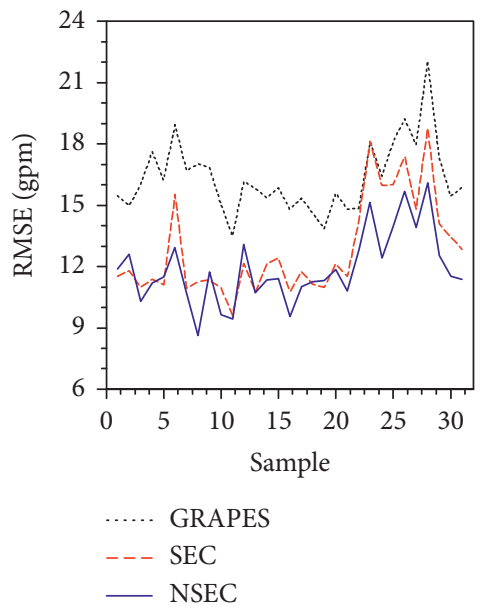

(f)

Figure 6: RMSE of $500 \mathrm{hPa}$ geopotential height of $48 \mathrm{~h}$ forecast at January (a, b, and c) and July (d, e, and f) of 2008, 2009, and 2010. The black lines (GRAPES) denote GRAPES model forecast, red lines (SEC) to the forecast after system correction, and blue lines (NSEC) to the forecast after correction of nonsystematic error.

TABLE 5: Average of RMSE of test samples of geopotential height on $500 \mathrm{hPa}$ (unit: gpm).

\begin{tabular}{lccc}
\hline Test month & GRAPES model & Systematic error correction & Nonsystematic error correction \\
\hline 2008 Jan. & 17.297 & 15.406 & 13.786 \\
2009 Jan. & 18.279 & 15.880 & 14.438 \\
2010 Jan. & 18.909 & 16.007 & 14.161 \\
2008 Jul. & 15.091 & 12.226 & 11.397 \\
2009 Jul. & 16.389 & 12.340 & 12.038 \\
2010 Jul. & 16.323 & 12.839 & 11.886 \\
\hline
\end{tabular}

TABLE 6: Ratio distribution of RMSE of $48 \mathrm{~h}$ forecast of geopotential height on $500 \mathrm{hPa}$ between corrected forecast and the forecast of model.

\begin{tabular}{lcccccc}
\hline Correction process & $0.5-0.6$ & $0.6-0.7$ & $0.7-0.8$ & $0.8-0.9$ & $0.9-1.0$ & $>1.0$ \\
\hline Systematic error & 2 & 24 & 69 & 51 & 18 & 22 \\
Nonsystematic error & 9 & 39 & 82 & 40 & 11 & 5 \\
\hline
\end{tabular}

3.5. Further Study on Temperature. This variational approach depends on the character of time tendency of variables. To verify the repeatability of the variational approach, experiments are conducted on the temperature and show a similar result to the geopotential height.
Figure 7 gives one sample of the estimation of the temperature of $24 \mathrm{~h}$ forecast on $500 \mathrm{hPa}$ on July 6, 2010. It shows that the method has favourable estimation ability for the nonsystematic error of this sample. The estimated value has basically consistent spatial distribution 


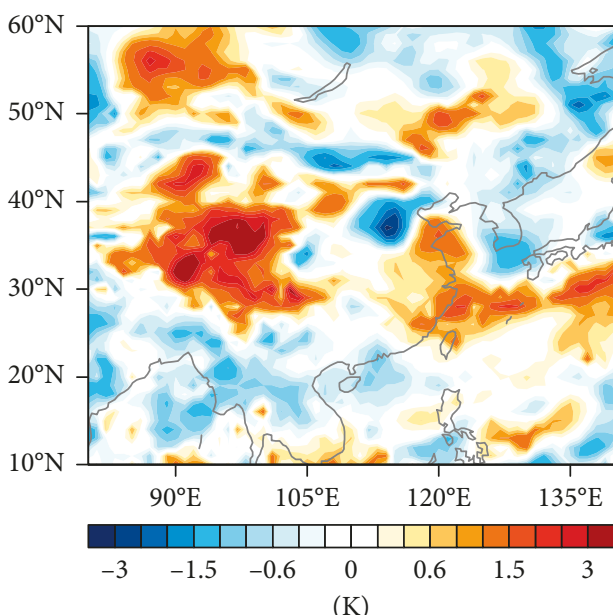

(a)

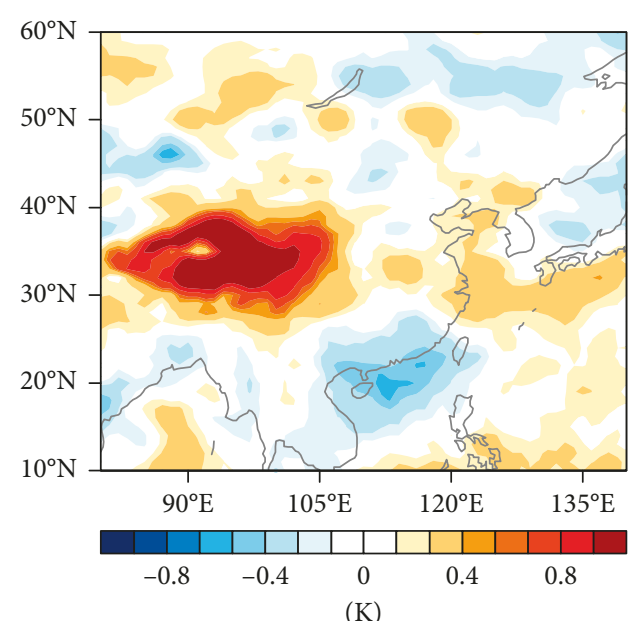

(b)

FiguRE 7: $24 \mathrm{~h}$ nonsystematic error of temperature on $500 \mathrm{hPa}$ on July 6, 2010 (unit: K): (a) nonsystematic error and (b) nonsystematic error estimated by variational approach.

characteristic with that of the real one. For example, in positive value area, in the Qinghai-Tibet Plateau, negative value area in the East China Sea, and its east of the Pacific Ocean, they have good consistency with the real field, with a little smaller magnitude like the geopotential height. The RMSE of this sample sees a fall from $0.878 \mathrm{~K}$ to $0.860 \mathrm{~K}$ after correction of systematic error, and it goes down to $0.764 \mathrm{~K}$ after further correction of nonsystematic error. It means that the estimation of nonsystematic error of this sample is effective. The estimated nonsystematic error has main character of the real one, and the correction can effectively improve the forecast based on systematic error correction.

Figure 8 is the RMSE change of temperature of $24 \mathrm{~h}$ forecast on $500 \mathrm{hPa}$ in January and July of 2008, 2009, and 2010. Almost all the samples have a positive change after the systematic error correction (180 out of 186 samples). RMSE decreases gradually after the correction of nonsystematic error, which confirms this method's positive effect on the forecast error correction of another variable.

The average of RMSE of forecast in Table 7 shows that the correction of nonsystematic error can improve forecast effectively. For instance, the average of RMSE of GRAPES model in January 2008 is $0.948 \mathrm{~K}$. After system error correction, it decreases to $0.769 \mathrm{~K}$. After further correction of nonsystematic error estimated by variational approach, it declines to $0.741 \mathrm{~K}$. Correction effects of forecast by variational approach in other experiments are similar to the result in January 2008.

Table 8 is the distribution of ratios of $24 \mathrm{~h}$ forecast of temperature in January and July of 186 samples. It indicates that the ratio of valid correction of systematic error is $96.774 \%$, increasing to $98.387 \%$ after nonsystematic error correction. The number of samples corrected effectively (the ratio is below 0.8 ) by nonsystematic error increases from 106 to 125 , and the number of samples with invalid correction reduces from 6 to 3. Variational approach is also useful for the temperature variable.
To access the accuracy of the variational approach, the upper air observational temperature from MICAPS is used to verify the forecast after correction by calculating the RMSE between the forecast (interpolating to the observational upper air station) and the observational temperature, which is shown in Figure 9. It indicates that both systematic error correction and nonsystematic error correction reduce the RMSE compared to the GRAPES forecast, while the improvement from systematic error correction to nonsystematic error correction is not that obvious. If we use the historical observational data to correct the forecast, it may have a better performance.

\section{Conclusions}

In this study, we proposed variational method to estimate nonsystematic model error and eliminate it by adopting historical analysis data, different from known model correction methods. Experiments are conducted for the study with the data in January and July from 2002 to 2010 of the GRAPES model forecast and NCEP FNL analysis. Forecast error is divided into two parts: systematic error and nonsystematic error.

(1) Preliminary analysis about spatial characteristics of forecast error is carried out in East Asia. The nonsystematic forecast error in GRAPES model has obvious characteristic of state dependency. The nonsystematic forecast error changes along season and the state of weather and makes up about half of the total forecast error.

(2) Using the variational approach, we obtain the nonsystematic forecast error estimation of GRAPES model, which is well corresponding to the real field. Of the total 186 sample tests of $24 \mathrm{~h}$ forecast, $91.935 \%$ and $96.273 \%$ show a significant amelioration after systematic error correction and nonsystematic error correction of RMSE, respectively. As for $48 \mathrm{~h}$ 


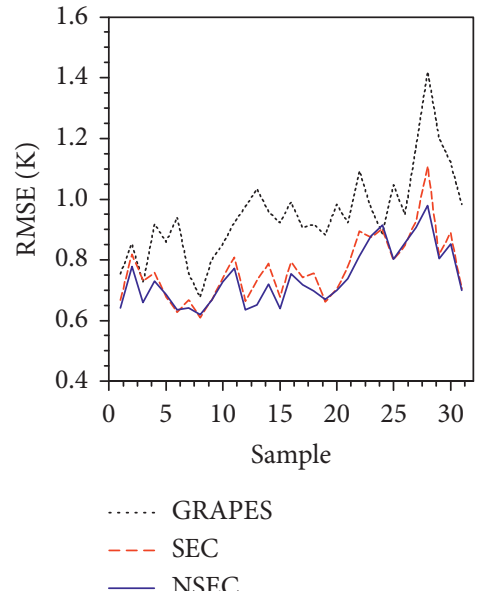

(a)

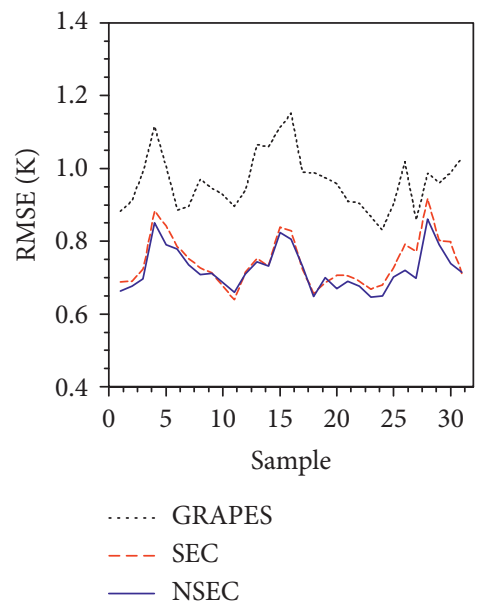

(d)

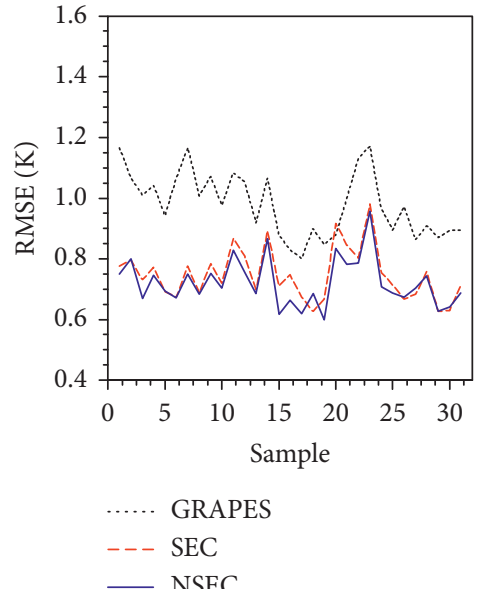

(b)

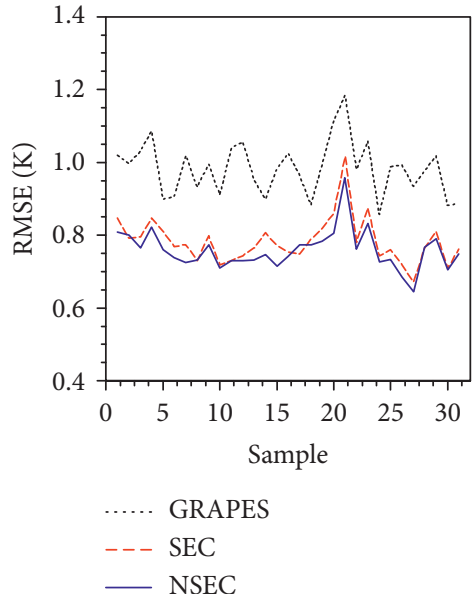

(e)

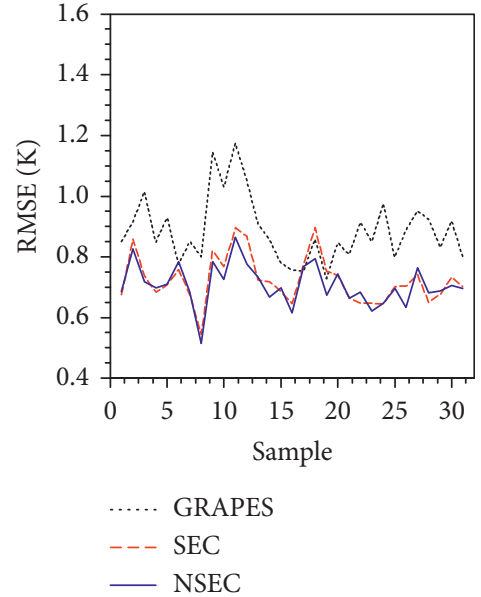

(c)

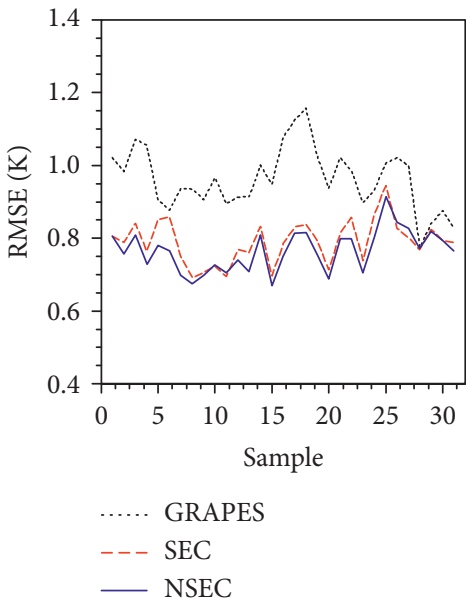

(f)

FIGURE 8: RMSE of $500 \mathrm{hPa}$ temperature of $24 \mathrm{~h}$ forecast at January (a, b, and c) and July (d, e, and f) of 2008, 2009, and 2010. The black lines (GRAPES) denote GRAPES model forecast, red lines (SEC) to the forecast after system correction, and blue lines (NSEC) to the forecast after correction of nonsystematic error.

TABLE 7: Average of RMSE of test samples of temperature on $500 \mathrm{hPa}$ (unit: K).

\begin{tabular}{lccc}
\hline Test month & GRAPES model & Systematic error correction & Nonsystematic error correction \\
\hline 2008 Jan. & 0.948 & 0.769 & 0.741 \\
2009 Jan. & 0.979 & 0.748 & 0.722 \\
2010 Jan. & 0.888 & 0.724 & 0.708 \\
2008 Jul. & 0.966 & 0.743 & 0.723 \\
2009 Jul. & 0.983 & 0.783 & 0.759 \\
2010 Jul. & 0.962 & 0.791 & 0.766 \\
\hline
\end{tabular}

TABLE 8: Distribution of ratios of RMSE of corrected $24 \mathrm{~h}$ forecast of temperature on $500 \mathrm{hPa}$ to the forecast of GRAPES model.

\begin{tabular}{lccccc}
\hline Correction process & $0.6-0.7$ & $0.7-0.8$ & $0.8-0.9$ & $0.9-1.0$ & $>1.0$ \\
\hline Systematic error & 14 & 92 & 59 & 15 & 6 \\
Nonsystematic error & 27 & 98 & 44 & 14 & 3 \\
\hline
\end{tabular}

forecast, the correction efficiency proportion of samples increases from $88.172 \%$ of systematic error correction to $97.311 \%$ of nonsystematic error correction. The new method reduces the RMSE.
Moreover, the approach proposed in this paper is more efficiency than the method of DEM, which corrects the forecast by building the relationship between the nonsystematic and the forecast field combination. This method is efficient by using the character of time tendency of the geopotential height.

(3) To verify the repeatability of the variational approach, experiments are conducted on the $24 \mathrm{~h}$ forecast error correction of temperature on $500 \mathrm{hPa}$. The correction 


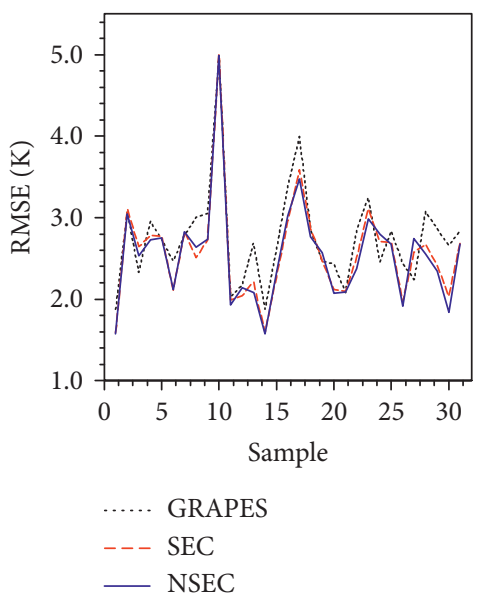

(a)

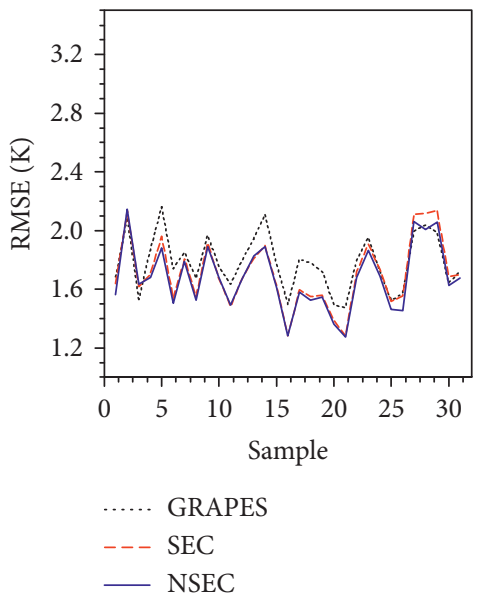

(d)

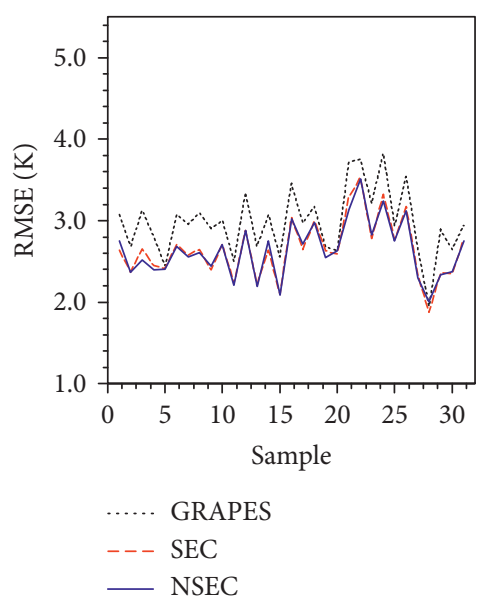

(b)

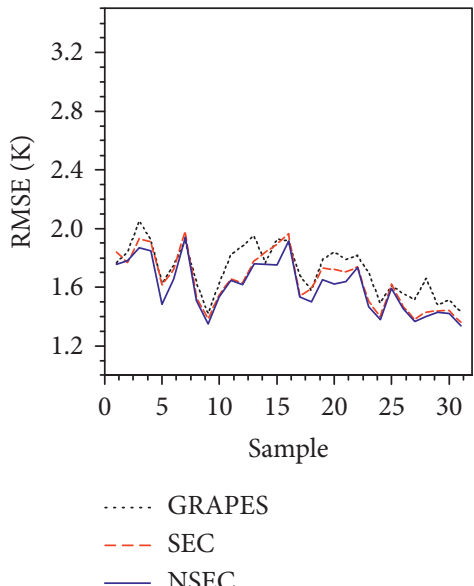

(e)

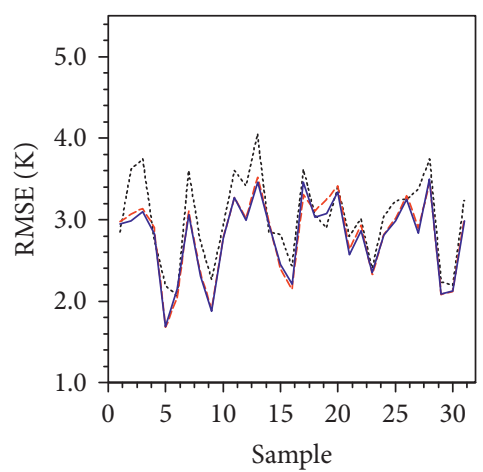

.... GRAPES

-- SEC

— NSEC

(c)

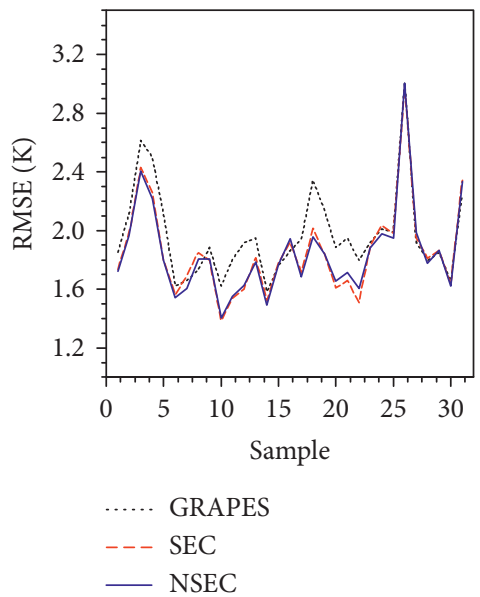

(f)

FIGURE 9: RMSE of $500 \mathrm{hPa}$ temperature of $24 \mathrm{~h}$ forecast at January (a, b, and c) and July (d, e, and f) of 2008, 2009, and 2010, regarding the observational upper air temperature from MICAPS as the truth. The black lines (GRAPES) denote GRAPES model forecast, red lines (SEC) to the forecast after system correction, and blue lines (NSEC) to the forecast after correction of nonsystematic error.

efficiency proportion of samples of systematic error correction is $96.774 \%$, increasing to $98.387 \%$ after the nonsystematic error correction. By comparing the forecast to the upper air observational data from MICAPS, the variational approach is confirmed to be efficient. With the increase of the convenience of the acquisition of observational data, applying the observation data to the error correction is possible.

(4) In consideration of the principle of this method, it could be useful for the other variables that have the character of time tendency. The experiments on temperature verify this conclusion. In the future, we would like to apply this method to a combination of some variables of different heights. This new error correction method is effective for GRAPES model, and further experiments may confirm that this method can be applied to other reasonable weather forecast models or ensemble NWP for longer-term applications. It provides an alternative tool to improve numerical predictions with historical analysis or observational data.

\section{Data Availability}

The data used to support the findings of this study are available from the corresponding author upon request.

\section{Conflicts of Interest}

The authors declare that there are no conflicts of interest regarding the publication of this paper.

\section{Acknowledgments}

This research was funded by the National Key R\&D Program of China (2018YFC1507200), NSFC Project under grant 41620104009, Science and Technology Funds (2018Q04), and Key projects (2018Z05) of Hubei Meteorological Bureau.

\section{References}

[1] A. C. Lorenc, "Analysis methods for numerical weather prediction," Quarterly Journal of the Royal Meteorological Society, vol. 112, no. 474, pp. 1177-1194, 1986. 
[2] M. Ghil and P. Malanotte-Rizzoli, "Data assimilation in meteorology and oceanography," Advances in Geophysics, vol. 33, pp. 141-266, 1991.

[3] P. L. Houtekamer and H. L. Mitchell, "Data assimilation using an ensemble Kalman filter technique," Monthly Weather Review, vol. 126, no. 3, pp. 796-811, 1998.

[4] E. Kalnay, Atmospheric Modelling, Data Assimilation and Predictability, Cambridge University Press, Cambridge, UK, 2003.

[5] C. Qiu and J. Chou, "The analogic-dynamical method of forecasting weather," Chinese Journal of Atmospheric Sciences, vol. 13 , no. 1 , pp. $20-28,1989$.

[6] J. Chou and H. Ren, "Numerical weather prediction-necessity and feasibility of an alternative methodology," Journal of Applied Meteorological Science, vol. 17, no. 2, pp. 240-244, 2006.

[7] J. C. Derber, "A variational continuous assimilation technique," Monthly Weather Review, vol. 117, no. 11, pp. 24372446, 1989.

[8] Z. Yin, T. Peng, F. Yang et al., "The preliminary experiment of genetic-neural network flood forecasting based on QPE and QPF," Torrential Rain and Disasters, vol. 32, no. 4, pp. 360368, 2013.

[9] J. Chou, Some Problems of Long-Term Numerical Weather Prediction, p. 277, Water Resources and Electric Power Press, China, 1979.

[10] J. Huang, Y. Yi, S. Wang et al., “An analogue-dynamical longrange numerical weather prediction system incorporating historical evolution," Meteorological Society, vol. 119, pp. 547-565, 1993.

[11] H. Yu, J. Huang, W. Li et al., "Development of the analoguedynamical method for error correction of numerical forecasts," Acta Meteorologica Sinica, vol. 72, no. 5, pp. 1012-1022, 2014.

[12] X. Peng, Y. Che, and J. Chang, "A novel approach to improve numerical weather prediction skills by using anomaly integration and historical data," Journal of Geophysical Research: Atmospheres, vol. 118, no. 16, pp. 8814-8826, 2013.

[13] D. Zupanski and M. Zupanski, "Model error estimation employing an ensemble data assimilation approach," Monthly Weather Review, vol. 134, no. 5, pp. 1337-1354, 2006.

[14] G. Holland, J. Done, C. Bruyere et al., "Model investigations of the effects of climate variability and change on future Gulf of Mexico tropical cyclone activity," in Proceedings of the Annual Offshore Technology Conference, Houston, TX, May 2010.

[15] Z. F. Xu and Z.-L. Yang, "An improved dynamical downscaling method with GCM bias corrections and its validation with 30 years of climate simulations," Journal of Climate, vol. 25, no. 18, pp. 6271-6286, 2012.

[16] Y. R. Gel, "Comparative analysis of the local observationbased (LOB) method and the nonparametric regression-based method for gridded bias correction in mesoscale weather forecasting," Weather and Forecasting, pp. 243-1256, 2007.

[17] J. P. Hacker and D. L. Rife, "A practical approach to sequential estimation of systematic error on near-surface mesoscale grids," Weather and Forecasting, vol. 22, no. 6, pp. 1257-1273, 2007.

[18] N. Yussouf and D. J. Stensrud, "Prediction of near-surface variables at independent locations from a bias-corrected ensemble forecasting system," Monthly Weather Review, vol. 134, no. 11, pp. 3415-3424, 2006.

[19] W. Y. Y. Cheng and W. J. Steenburgh, "Strengths and weaknesses of MOS, running-mean bias removal, and kalman filter techniques for improving model forecasts over the western United States," Weather and Forecasting, vol. 22, no. 6 , pp. 1304-1318, 2007.

[20] C. E. Leith, "Objective methods for weather prediction," Annual Review of Fluid Mechanics, vol. 10, no. 1, pp. 107-128, 1978.

[21] C. M. Danforth, E. Kalnay, and T. Miyoshi, "Estimating and correcting global weather model error," Monthly Weather Review, vol. 135, no. 2, pp. 281-299, 2007.

[22] C. M. Danforth and E. Kalnay, "Using singular value decomposition to parameterize state-dependent model errors," Journal of the Atmospheric Sciences, vol. 65, no. 4, pp. 1467$1478,2008$.

[23] A. Shao, S. Xi, and C. Qiu, "Variational method to correct the forecast error of numerical model," Science in China Series D-Earth Sciences, vol. 39, no. 2, pp. 235-244, 2009.

[24] H. Li, A. Shao, D. He et al., "Application of back-propagation neural network in predicting non-systematic error in numerical prediction model," Plateau Meteorology, vol. 34, no. 6, pp. 1751-1757, 2015.

[25] Z. Wang, X. Xu, N. Xiong et al., "GPU acceleration for GRAPES meteorological model," in Proceedings of the 2011 IEEE 13th International Conference on High Performance Computing and Communications (HPCC), pp. 365-372, Banff, Alberta, Canada, September 2011. 

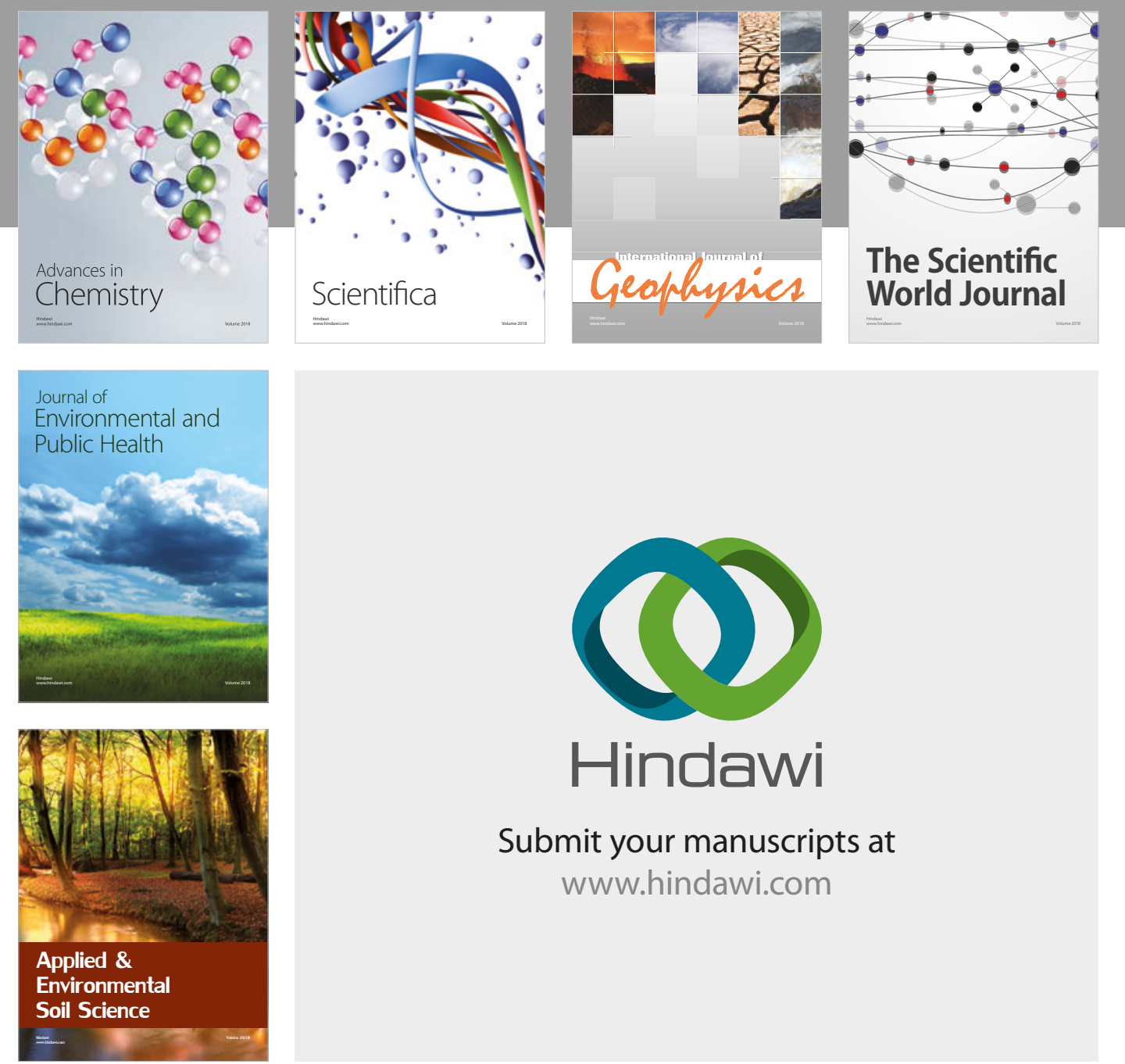

The Scientific

\section{World Journal}
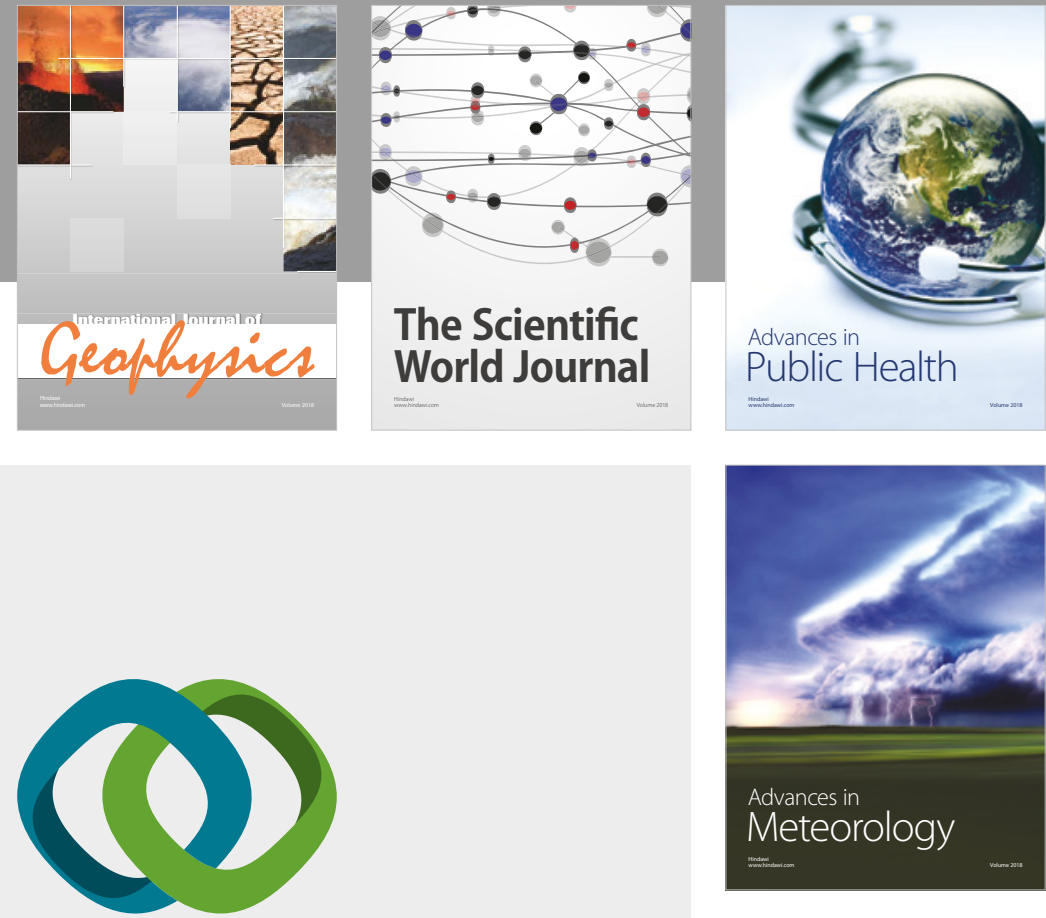

Advan

Public Health

\section{Hindawi}

Submit your manuscripts at

www.hindawi.com
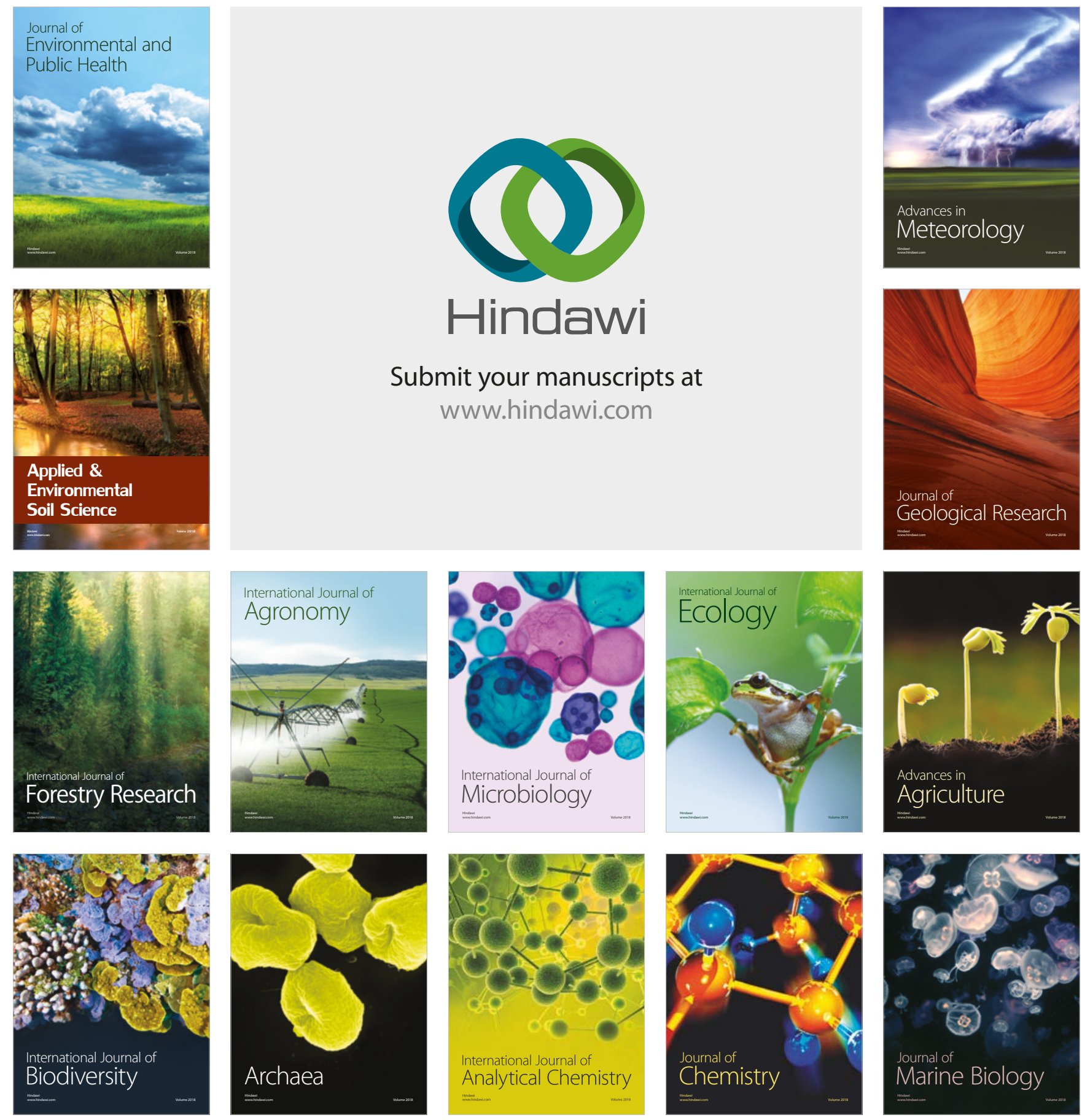